\title{
CURIMATÃ-PACU COMO ESPÉCIE PREFERIDA PELOS CONSUMIDORES EM FEIRAS LIVRES DO BAIXO RIO SÃO FRANCISCO, ALAGOAS - BRASIL
}

\author{
D. DE M. ARAÚJO ${ }^{1}$, L. T. O. TAMANO ${ }^{2}$, C. W. S. DO NASCIMENTO 3 , K. A. S. TAVARES ${ }^{4}$, J. L. F. LINS 5 , J. DA SILVA 6 \\ Instituto Federal de Alagoas ${ }^{1,3,4,6}$, Universidade de São Paulo ${ }^{2}$, Universidade Federal de Alagoas ${ }^{5}$ \\ ORCID ID: http://orcid.org/0000-0003-0700-98361 \\ daniel.araujo@ifal.edu.br ${ }^{1}$
}

Submetido 03/01/2020 - Aceito 13/08/2020

DOI: $10.15628 /$ holos.2020.9358

\section{RESUMO}

Foram entrevistados 104 e 105 consumidores de peixes nas feiras livres de Penedo (PEN) e Porto Real do Colégio (PRC), Alagoas. Dentre aqueles que afirmaram a preferência pela curimatã-pacu (16 e 27 consumidores), houve uma segunda entrevista para a caracterização socioeconômica e de suas preferências de aquisição e consumo. Homens conformaram a maioria dos entrevistados nas duas cidades, sendo as médias de idade 47,64 e 54,64 anos. Baixas escolaridade e renda familiar foram características comuns. Em ambas as localidades, as carnes preferidas indicadas foram bovinos $(47,06 \%$ e $48,00 \%)$ e peixes $(29,41 \%$ e $36,00 \%)$. Dentre os consumidores que declararam ser a curimatã-pacu a sua espécie predileta, a frequência de consumo de peixes era alta, sendo que $64,71 \%$ em PEN e $76,00 \%$ em PRC declararam que consumiam mais de uma vez por semana. Além das curimatãs-pacu, as outras espécies mais citadas como preferidas foram: tambaqui, piaus e tilápia do Nilo (36,36\%; 36,36\% e 18,18\% em PEN; $26,32 \% ; 42,11 \%$ e $21,05 \%$ em PRC). A maioria que declarou preferir consumir a espécie, afirmou a preferência por sua compra ainda viva ou inteiras frescas, vindo a considerar $\mathrm{R} \$ 6,90$ e $\mathrm{R} \$ 6,46$ os valores justos pelo quilograma de peixes e as quantias de $R \$ 8,37$ e $R \$ 8,25$ como os preços justos para as curimatãs-pacu, em PEN e PRC, respectivamente. Sendo a espécie nativa preferida nas duas cidades e o mais importante recurso íctico explotado na região, uma maior atenção deve ser dada ao processo de comercialização com vistas a possibilitar a conservação da curimatã-pacu.

PALAVRAS-CHAVE: Cadeia produtiva de pescados, Consumidor de peixe, Oreochromis niloticus, Preferência de consumo de peixe, Prochilodus argenteus.

\section{CURIMATÃ-PACU AS FAVORITE SPECIE BY THE CONSUMERS ON THE STREET MARKETS AT THE LOWER SÃO FRANCISCO RIVER, ALAGOAS - BRAZIL}

\begin{abstract}
In order to characterize the commercialization of the curimatã-pacu, 104 and 105 fish consumers were interviewed at the street markets of Penedo (PEN) and Porto Real do Colégio (PRC), Alagoas. Among those who declared having a preference for curimatã-pacu (16 and 27 consumers), there was a second interview for socioeconomic characterization of their preferences for acquisition and consumption. Men conformed the majority of nterviewed in both cities, being the average age 47.64 and 54.64 years. Low education level and family income were common characteristics. In both localities, the preferred meats indicated were beef (47.06\% and $48.00 \%)$ and fish $(29.41 \%$ and $36.00 \%)$. Among the consumers who declared curimatã-pacu to be their favorite species, the frequency of fish consumption was high, with $64.71 \%$ in PEN and $76.00 \%$ in PRC, reporting that they consumed more than once a week. In addition to the curimatãs-pacu, the other species most
\end{abstract}

cited as preferred were tambaqui, piaus and Nile tilapia (36.36\%; 36.36\% and $18.18 \%$ in PEN; $26.32 \%$; $42.11 \%$ and $21.05 \%$ in RPC). The majority who stated that they prefer to consume the curimatãs-pacu, affirmed the preference for their purchase still alive or whole fresh, considering $\mathrm{R} \$ 6.90$ and $\mathrm{R} \$ 6.46$ the fair values per kilogram of fish and the amounts of $R \$ 8.37$ and $R \$ 8.25$ as the fair prices for curimatãs-pacu, in PEN and PRC, respectively. Being the preferred native specie in both cities, and the most important exploited fish stock in the region, greater attention should be given to the commercialization process to provide the conservation of curimatã-pacu.

KEYWORDS: Fish consumer, Oreochromis niloticus, Preference of fish consume, Prochilodus argenteus, Productive fish chain. 


\section{INTRODUÇÃO}

Desde o período colonial que as feiras livres se fazem presentes na vida cotidiana brasileira. Nas ruas, transeuntes e vendedores trocavam suas mercadorias: as mulheres negras, forras ou escravizadas, com seus quitutes variados; utensílios domésticos; as ferramentas de trabalho. Uma movimentação de pessoas, de artigos de vendas, da economia. A feira consistia em um espaço de sociabilidades, portanto, não limitada ao aspecto comercial. Elas conectavam pessoas, dinamizavam o comércio, ampliavam possibilidades de acesso a determinados itens, atuando, como definiram Mascarenhas e Dalzani (2008), um serviço de utilidade pública, uma vez que voltadas para a distribuição local de gêneros alimentícios.

Com a República, a imposição dos preceitos higiênicos depositou sob as feiras livres a necessidade de se adaptarem à modernidade. Um ordenamento organizacional, espacial e higiênico passou a ser imperativo aos feirantes pelas administrações públicas. No ímpeto de se mostrar e fazer apto aos novos tempos, as cidades passaram por modificações, com as ruas sendo tomadas pelos automóveis e trens, pelas mudanças na espacialidade urbana. Nessa realidade desenhada, as feiras se tornavam um elemento destoante nesse cenário e, mais do que isso, um entrave. Simbolizavam, ainda, a persistência do "atraso" e da presença das camadas pobres inferiorizadas que se queriam esconder. Mas elas persistiram e persistem no cenário urbano, como uma contramola. Como afirmaram Mascarenhas e Dolzani (2008), tal resistência é permitida pelos os que dela precisam para sobreviverem materialmente falando, e por aqueles que zelam pela sobrevivência sociocultural.

Na cidade de Penedo - Alagoas, a feira livre é um importante canal de comercialização para variados tipos de produtos, dentre os quais destaca-se aqui a venda de peixes. Cidade ribeirinha, teve e continua tendo com o Rio São Francisco uma ligação forte e mesmo intrínseca, seja pelos organismos que o rio oferta, seja pela dinamização comercial que oportuniza. A feira é diária, porém é no sábado que há uma maior movimentação de clientes e feirantes, inclusive, alguns vindo do Estado de Sergipe. A venda de peixes na feira ocorre quase exclusivamente aos sábados, sendo realizada diariamente no Mercado de Peixes do município, nas proximidades da feira.

A feira congrega dez ruas da região central da cidade e não há uma divisão oficial demarcada, todavia há uma ordenação espacial por segmento de venda. Ela divide o espaço com lojas, restaurantes, supermercados, açougues, demonstrando uma dinamicidade dentro da organização da própria cidade. É na rua Francisco Freire que estão situadas as barracas de venda de peixes. Este espaço não está devidamente estruturado para a venda dos pescados, principalmente levando em consideração as condições sanitárias. Naquelas são comercializados diferentes tipos de pescados: peixes, camarões, sururu, maçunim, caranguejos, sejam provenientes do mar, do cativeiro ou do Velho Chico.

A mesma relação com o Rio São Francisco pode ser apreendida quando se aborda a cidade de Porto Real do Colégio - Alagoas, sendo ambas vizinhas e pertencentes à região do Baixo São Francisco, o que justifica as similaridades. Segundo Lustosa et al. (2008), esta região se destaca entre os principais polos de aquicultura do país. Em decorrência de seu alto potencial para a atividade, 
diversos municípios da região integraram o Arranjo Produtivo Local de Piscicultura de Alagoas, que tem como objetivo a integração dos diferentes entes e elos da cadeia produtiva da atividade a fim de promovê-la (Araujo et al., 2015). Diferente da feira livre de Penedo, nesta cidade ela é realizada somente às sextas-feiras, consubstanciando o maior polo livre de comercialização de alimentos do município, no qual os pescados estão incluídos.

Ainda que margeadas pelo São Francisco, em ambas as cidades há a comercialização de espécies de peixes não nativas da região, a exemplo de organismos marinhos que adentram ao rio (eurialinos), daqueles capturados no mar e levados à feira para a venda, bem como de espécies dulciaquícolas oriundas da piscicultura e/ou da pesca, por serem espécies exóticas estabelecidas na região. Podem-se destacar os tucunarés (Cichla spp.) e as tilápias do Nilo (Oreochromis niloticus) como espécies estabelecidas no Rio São Francisco, bem como a própria tilápia e o tambaqui como as mais importantes espécies da piscicultura local. Entretanto, dentre as espécies nativas da região, os piaus e a curimatã-pacu (Prochilodus argenteus) ganham destaque, seja de origem extrativista ou de aquicultura.

A região do Baixo São Francisco é uma importante área de pesca para as populações tradicionais, bem como o principal lócus para a piscicultura em várias partes do Nordeste brasileiro. Contudo, com relação à pesca, Sousa (2018) destacou que ações antrópicas promovem acentuado declínio e até o desaparecimento de boa parte das espécies comerciais, e que isso tem resultado no aumento da demanda pelas espécies que eram anteriormente desvalorizadas, tornando-as alvos da pesca. Para o autor, além da crescente procura pelo piau-preto (Leporinus piau) e pela curimatãpacu, outras espécies têm sido requisitadas, a exemplo dos caris (família Loricariidae, Hypostomus spp.; Loricaria spp.), pacamãs (Lophiosilurus alexandri) e pacus-verdadeiros (Piaractus mesopotamicus). O autor afirma que há relatos de depleção de todas as espécies supracitadas e até mesmo de desaparecimento em algumas localidades. É diante deste contexto ecológico descrito que se buscou entender a preferência dos frequentadores das feiras livres estudadas pelo consumo da curimatã-pacu, a qual tem sido uma espécie valorada no mercado local.

Devido à importância histórica e cultural das feiras livres e de sua relevância para as vendas no varejo, sabendo-se que nelas se concentra a comercialização de considerável parcela das curimatãs-pacu oriundas da pesca e da piscicultura nos municípios em questão, entende-se que é imprescindível compreender como se dá este processo. Conhecer o processo de comercialização da espécie na região pode ser importante tanto para a conservação da espécie, enquanto nativa da Bacia do Rio São Francisco, como também para munir pesquisadores, comerciantes, piscicultores e gestores locais de informações mais precisas sobre a preferência dos consumidores pela espécie. Assim, com o presente estudo, teve-se por objetivo analisar diversos aspectos da comercialização das curimatãs-pacu nas feiras livres dos municípios alagoanos de Penedo e Porto Real do Colégio, tendo como escopo os consumidores que declaravam que esta espécie era a sua preferida para o consumo. 


\section{ASPECTOS BIOLÓGICOS E ECONÔMICOS DA CURIMATÃ-PACU}

Dentre os peixes da Ordem dos Characiformes, a Família Prochilodontidae possui larga distribuição na América do Sul, principalmente na metade Norte e Sul do Equador e Brasil (Nelson; Grande e Wilson (2016). Os Prochilodus apresentam o corpo fusiforme, comprido, de coloração prateada acinzentada, focinho peculiar e boca subterminal em forma de ventosa (Almeida et al., 2018). São peixes que possuem hábito alimentar detritívoro-iliófago, ingerindo grandes quantidades de lodo com matéria orgânica em fases avançadas de dissociação, juntamente com microrganismos, a partir de depósitos de fundo ou sobre substratos verticais (Lopes, 2010). No cultivo em piscicultura, são bem adaptados às rações comerciais para peixes onívoros.

Como destacado anteriormente, por serem peixes detritívoros, possuem uma grande importância ecológica. Neste sentido, Bowen (1983), em seu estudo, destaca o necessário papel destas comunidades de peixes no fluxo de energia, na ciclagem da matéria orgânica e na dinâmica populacional nos ecossistemas aquáticos. Ademais, de acordo com Martins (2017), Prochilodus é considerado o gênero íctico de maior importância na pesca artesanal brasileira. Baseando-se nesta informação, pode-se reportar às principais espécies deste grupo uma proporcional relevância socioeconômica para as populações ribeirinhas que dependem do seu extrativismo e da sua produção em cativeiro.

Dentre as espécies do gênero descrito, considerando o recorte geográfico do estudo, uma delas se reveste de notoriedade. A espécie Prochilodus argenteus (Spix \& Agassiz, 1829) é popularmente conhecida como curimatã-pacu, xira, curimbá, bambá ou zulega, possui o maior porte da família e pode atingir até $15 \mathrm{~kg}$ de peso corporal (Godinho \& Godinho, 2003). De acordo com Castro e Vari (2004), esta espécie é endêmica da bacia do Rio São Francisco, no Leste do Brasil, vindo a ser posteriormente introduzida em várias bacias hidrográficas do Nordeste brasileiro pelo Departamento Nacional de Obras Contra Secas (DNOCS).

Conforme descrevem Godinho e Godinho (2003), tanto a pesca quanto a produção em cativeiro da espécie em estudo nunca foi quantificada de forma exata, o que dificulta a apresentação de dados sobre a pesca e a piscicultura da curimatã-pacu em toda a bacia do rio São Francisco. Dentre os poucos estudos nos quais é possível obter informações sobre estatísticas pesqueiras de animais deste gênero, podem-se destacar os de Campos (2009), que apontou a curimatã-pacu como a espécie responsável por cerca de $50 \%$ da produção pesqueira da referida bacia hidrográfica; bem como o de Soares et al. (2011), que a destacam como a que representa $40 \%$ da biomassa explorada na região de Penedo - AL entre 2017 e 2009.

Ainda que Godinho e Godinho (2003) apontem para a necessidade de estudos técnicos e acadêmicos com a finalidade de obtenção de dados da produção da curimatã-pacu, baseando-se na literatura já disponível, pode-se inferir que, sob o ponto de vista socioeconômico, a espécie é destacada fonte de geração de renda para os pescadores da região do Baixo rio São Francisco. Segundo Almeida et. al. (2018), são muitos os pescadores e comerciantes que auferem suas rendas exclusivamente da cadeia produtiva deste organismo. Além da captura artesanal, a criação da espécie se dá de forma extensiva e semi-intensiva, caracterizada pela produção familiar de subsistência e pelo comércio em feiras livres nas sedes municipais. 
Araujo et al. (2018a) destacaram que a pesca na região da bacia hidrográfica do Rio São Francisco é de extrema importância para a subsistência e geração de renda para as populações locais. Tal fato predomina ainda que, conforme os referidos autores, a pesca tenha decaído nos últimos anos devido às ações antrópicas geradas pela expansão territorial, o desmatamento de mata ciliar, o despejo de matéria orgânica oriunda da falta de saneamento básico e da expansão de hidroelétricas que dificultam a conservação das espécies. Para estes autores, nestas condições de declínio da pesca, a piscicultura também passou a se destacar enquanto atividade econômica de maneira ainda mais substancial na região.

As populações tradicionais de cidades e povoados ribeirinhos possuem o hábito alimentar ligado à pesca. À vista disso, Araújo et al. (2018b) constataram que os peixes representam a segunda escolha dos consumidores entrevistados em feiras livres do Baixo Rio São Francisco, em se tratando de preferência para o consumo de proteínas de origem animal, perdendo apenas para a carne bovina. Com relação às preferências de consumo de espécies particulares de peixes em cidades alagoanas banhadas pelo Rio São Francisco, Araújo et al. (2018a, b) demonstraram que a curimatãpacu é a terceira espécie predileta, perdendo apenas para a tilápia do Nilo e para o tambaqui (Colossoma macropomum), nesta ordem, no ranking de peixes preferidos por consumidores.

Diante do exposto, fica evidente a necessidade de maior conhecimento sobre o comportamento de consumidores em relação ao processo de aquisição da espécie como forma de proporcionar o entendimento necessário para regular a pesca (setor extrativista) e para fomentar a piscicultura desta espécie nas áreas banhadas pelas bacias hidrográficas de ocorrência da mesma.

\section{METODOLOGIA}

Este trabalho é o resultado de estudos realizados nos municípios de Penedo (PEN) e Porto Real do Colégio (PRC), Alagoas (Figura 1), voltados para a caracterização dos consumidores, suas preferências sobre os aspectos gerais de aquisição e o consumo de peixes em suas feiras livres, tendo como espécie alvo a curimatã-pacu. É válido pôr em relevo que a série de levantamentos de dados ocorreu, além do interesse pessoal dos pesquisadores, em virtude da demanda dos próprios piscicultores à Gestão do Arranjo Produtivo Local de Piscicultura de Alagoas, então repassada ao Instituto Federal de Alagoas em uma Rodada de Negócios promovida pelo SEBRAE - AL.

Anteriormente ao período de coleta de dados, foram realizadas incursões aos locais alvo da pesquisa para o seu reconhecimento, identificação dos feirantes e pontos de venda dos peixes, bem como das espécies comercializadas. Após o diagnóstico inicial das feiras livres e tendo como embasamento uma revisão da literatura, foi montado um questionário semiestruturado. Este instrumento de coleta de dados foi testado pelos pesquisadores com os consumidores em situação real de compra $(n=10)$, sendo solicitada a avaliação destes sobre possíveis dificuldades para o entendimento das questões e o fornecimento das informações. Após essa primeira fase, foi realizada uma análise crítica do questionário e das entrevistas prévias para a adoção de mudanças entendidas como necessárias para a consolidação da versão final.

Com os questionários já estruturados, os dados foram coletados nas feiras livres das cidades de PEN (aos sábados) e de PRC (às sextas-feiras), entre os meses de setembro e outubro de 2012. 
Neste período, foram realizadas três incursões visando à execução das entrevistas com os consumidores.
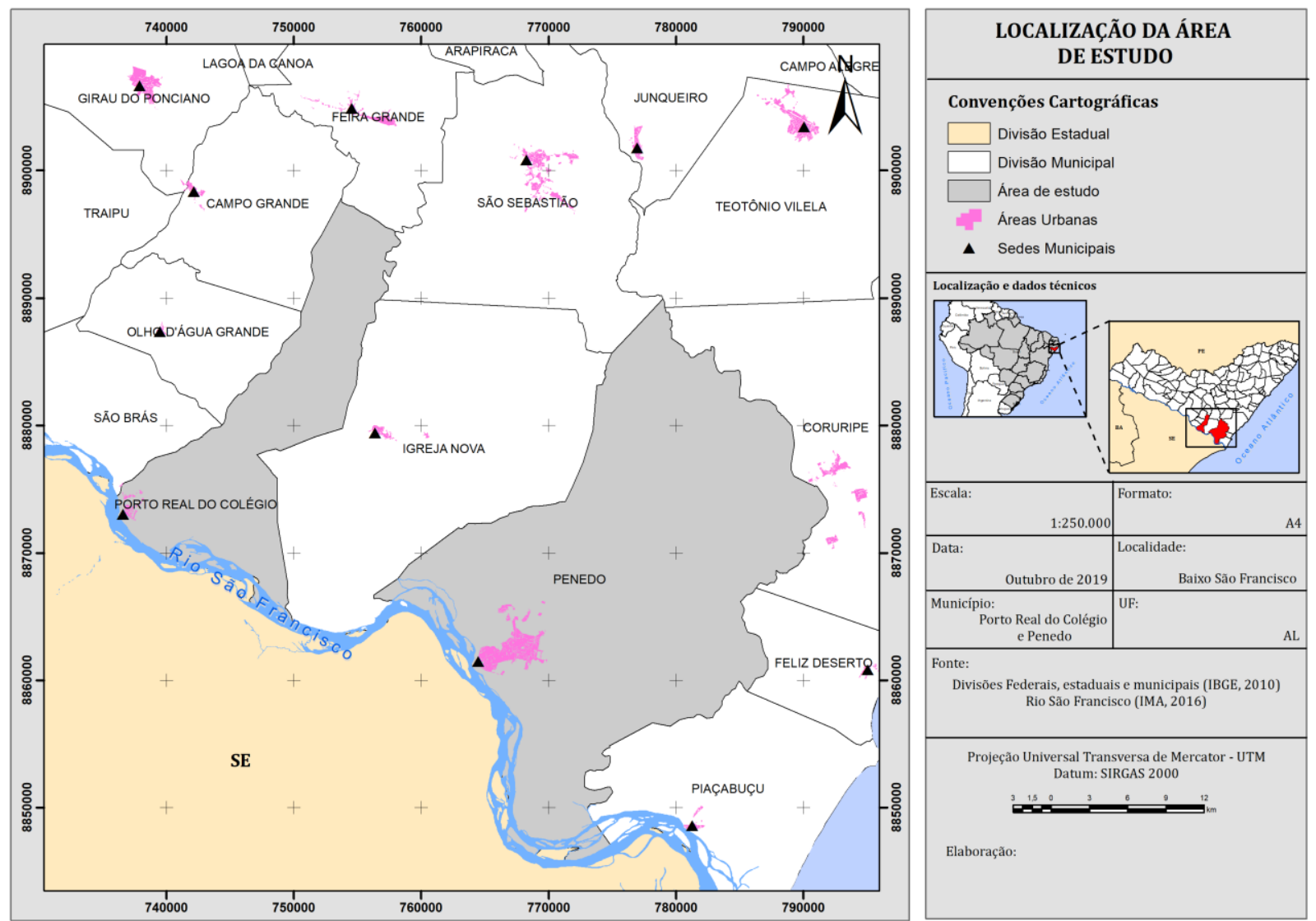

Figura 1: Municípios de Penedo e Porto Real do Colégio - Alagoas (destaque em cinza) onde foram entrevistados os consumidores nas feiras livres, sendo possível observar a localização em relação ao Rio São Francisco.

O questionário continha uma parte inicial, com vistas à caracterização geral do entrevistado (município em que reside, idade, sexo, estado civil, escolaridade, número de residentes por domicílio e renda mensal familiar); e questões mais direcionadas ao tema central do estudo (carne preferida, carne que consome com maior frequência, frequência de consumo de peixes, motivos para o consumo de peixes, se gostaria de consumir peixes mais vezes, tipo e espécie de peixes que prefere, percepções sobre o preço dos peixes, locais de compra, apresentação do pescado adquirido, propensão para compra de cortes especiais, propensão para valorização e aquisição de produção sustentável local, ocasiões de consumo, características da carne de peixe e consideração sobre possível dificuldade de preparo), totalizando-se 27 questões. Sempre que os consumidores entrevistados afirmavam ser a curimatã-pacu a sua espécie preferida para o consumo, eram realizadas mais nove perguntas específicas sobre a espécie (acerca da produção no município, a frequência de consumo, a preferência pela curimatã-pacu em detrimento dos outros peixes, a preferência de locais para aquisição, questões relacionadas ao preço e ao julgamento da qualidade da curimatã-pacu comercializada na feira livre).

De posse da versão final de ambos os questionários, geral e específico, novas incursões foram realizadas às feiras livres para que fossem coletados os dados. Foram abordados, de maneira 
aleatória, consumidores que transitavam pelas ruas ocupadas pelas bancas dos feirantes. A eles, os pesquisadores se identificaram, citando seu vínculo institucional, vindo a apresentarem brevemente a ideia central da pesquisa. As pessoas abordadas também eram informadas do caráter voluntário da pesquisa e que haveria o sigilo individual das informações, sendo estas somente divulgadas em valores médios, sendo impossível a identificação do entrevistado. Por conseguinte, somente aquelas pessoas que aceitaram os termos e condições explicitadas foram entrevistadas.

Como indicado, foram realizadas 104 entrevistas em PEN e 105 em PRC (total de 209 pessoas). Dentre esse total, 16 pessoas em Penedo e 27 pessoas em Porto Real do Colégio (total de 43 pessoas) afirmaram que a curimatã-pacu era a sua espécie preferida para o consumo e, para estas, foi solicitado que respondessem o questionário específico sobre àquela. Destaca-se que todos os valores apresentados neste estudo são oriundos dos consumidores que, ao responderem o primeiro questionário, afirmaram que a curimatã-pacu era a sua espécie favorita para o consumo (43 pessoas) e não ao total dos entrevistados (209 pessoas). As entrevistas foram realizadas entre 06h:00min e 13h:00min, em dois finais de semana (sextas-feiras e sábados, a depender da cidade), e duravam entre vinte e quarenta minutos cada.

Posteriormente à coleta, todas as respostas foram digitadas e contabilizadas em valores absolutos em planilhas eletrônicas, sendo, então, os valores transformados em percentagens. Os percentuais de cada resposta, não necessariamente, refletem o total de 16 ou de 27 entrevistados, mas o total de respostas obtidas em cada questão, tendo em vista que alguns compradores não responderam a todas as perguntas e que, além disso, para algumas perguntas era possível adotar mais de uma resposta. Os dados tabulados foram analisados por meio de estatística descritiva utilizando-se o software Excel $^{\circledR}$. Das planilhas eletrônicas, então, os dados foram utilizados para a confecção das tabelas de resultados apresentadas neste trabalho.

\section{RESULTADOS E DISCUSSÕES}

Como explicitado na metodologia deste trabalho, dentre os 104 e 105 entrevistados, 16 e 27 deles, ou $15,24 \%$ e $25,96 \%$ do total, respectivamente, em PEN e PRC, apontaram a curimatã-pacu como a espécie preferida. Ademais, dentre as pessoas que citaram outras espécies de peixes, a exemplo das tilápias do Nilo, tambaquis, piaus, dentre outros como suas preferidas, a curimatãpacu foi citada como a segunda espécie predileta por 13 (12,38\%) e 10 (9,61\%), respectivamente, para as cidades supracitadas (Figura 1).

São limitados os estudos sobre a comercialização de pescado que abordem a preferência alimentar dos consumidores considerando as espécies de peixe que mais gostam de consumir, dificultando comparações dentro e fora das cidades estudadas. Entretanto, em alguns trabalhos os pesquisadores correlacionam as espécies mais comercializadas como sendo estas as preferidas para o consumo. Neste contexto, Jesus et al. (2018) analisaram aspectos da comercialização de pescado em Feira de Santana - BA e observaram que tilápias e corvinas (Micropogonias furnieri) eram as espécies de peixe mais comercializadas. Um dos trabalhos no qual as espécies de peixes preferidas para o consumo foram descritas é o de Maciel et al. (2015), realizado em Corumbá - MS, onde as 
espécies mais consumidas foram o pacu (Piaractus mesopotamicus) e o pintado (Pseudoplatystoma corruscans).

Estudando a comercialização de peixes na feira livre da cidade de Penedo, Araujo et al. (2015a) afirmaram que a curimatã-pacu consistia na terceira espécie de maior preferência pelos consumidores, perdendo apenas para os tambaquis e para as tilápias, nesta ordem. De acordo com Soares et al. (2011), a curimatã-pacu correspondia a cerca de $40 \%$ dos desembarques em algumas localidades do Baixo Rio São Francisco, em 2011, sendo considerada por Santos et al. (2019) uma espécie bastante apreciada e comercializada pelas populações ribeirinhas. Tais informações denotam a dimensão de importância deste organismo enquanto recurso alimentar na região estudada e apontam para a necessidade de maior atenção para os aspectos de conservação da espécie em seu habitat nativo.

Outrossim, entendendo-se que o hábito alimentar é resultante de complexos fatores culturais, pode-se afirmar que a ocorrência natural de determinada espécie ou a disponibilidade de espécies aquícolas em determinada região é fator decisivo para o estabelecimento do hábito em consumi-la. Dessa maneira, é possível afirmar que uma espécie de peixe pode fazer cada vez mais parte das dietas das populações quanto mais frequentemente e em maiores quantidades estiver disponível, bem como quão mais acessível for o seu preço. Reforçando essa assertiva, Schneirder et al. (2014) apontaram que o consumo de carnes está intimamente relacionado à disponibilidade do alimento, preço, tradição, economia, influências religiosas e até mesmo à geografia do local.

Tabela 1: Caracterização dos consumidores entrevistados nas feiras livres de Penedo $(n=16)$ e de Porto Real do Colégio ( $n=27$ ), Alagoas - Brasil, e que citaram a curimatã-pacu como espécie de peixe preferida para o consumo.

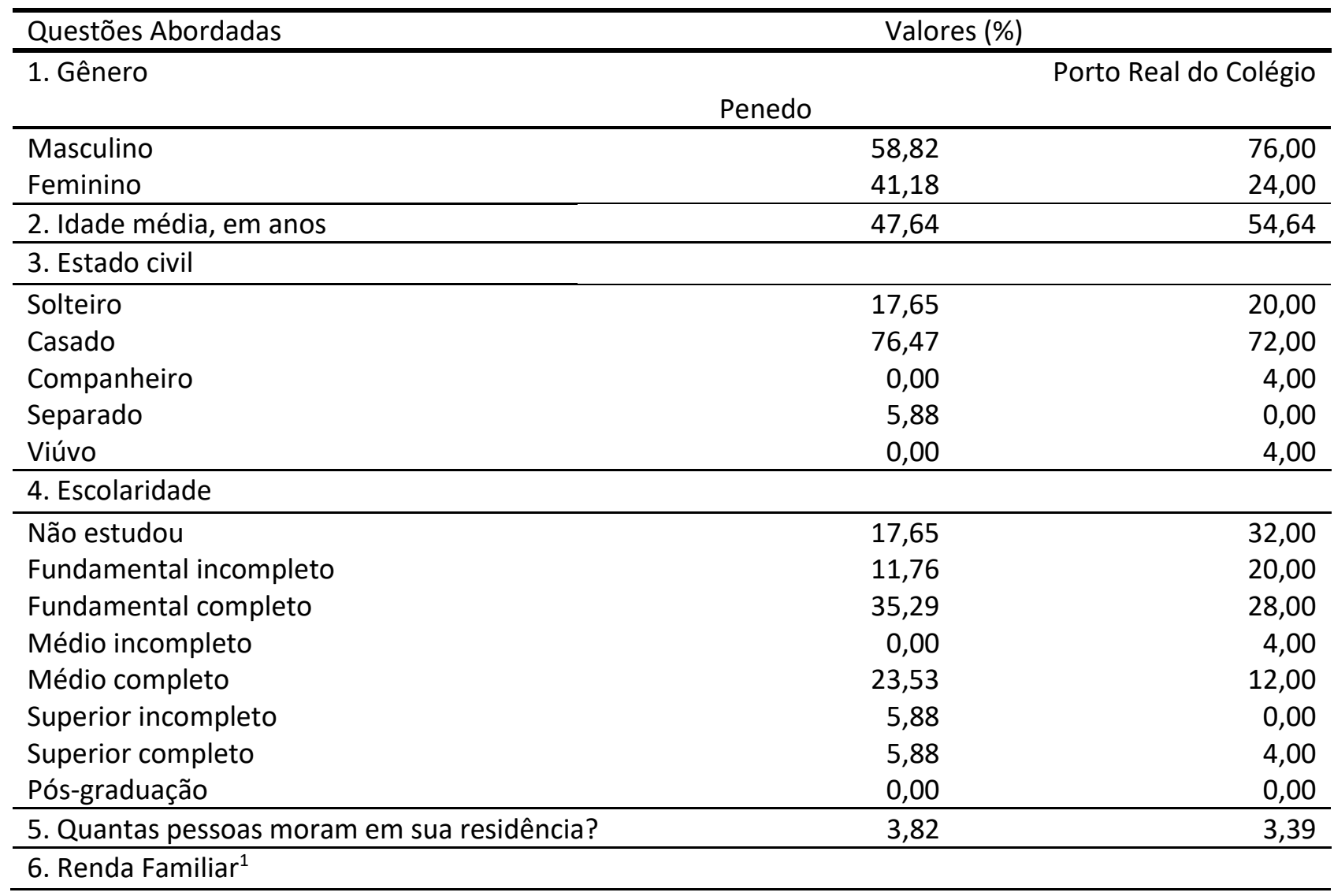




\begin{tabular}{lrr} 
Menor que um salário mínimo & 35,29 & 36,00 \\
Entre um e três salários mínimos & 41,18 & 60,00 \\
Entre três e seis salários mínimos & 23,53 & 0,00 \\
Entre seis e dez salários mínimos & 0,00 & 0,00 \\
Mais que dez salários & 0,00 & 4,00 \\
\hline 7. Quais as suas carnes preferidas? - Quais carnes consomem com maior frequência? & \\
\hline Bovina & $47,06-58,80$ & $48,00-56,00$ \\
Frango & $17,65-23,50$ & $16,00-16,00$ \\
Suína & $5,88-5,90$ & $0,00-0,00$ \\
Peixe & $29,41-11,80$ & $36,00-28,00$ \\
Caprina e/ou Ovina & $0,00-0,00$ & $0,00-0,00$ \\
Outras (exóticas, caça, etc) & $0,00-0,00$ & $0,00-0,00$ \\
\hline
\end{tabular}

Foram entrevistados 104 consumidores de peixes em Penedo e 105 em Porto Real do Colégio, dos quais, respectivamente, 16 e 27 entrevistados citaram a curimatã-pacu como a espécie preferida para o consumo. ${ }^{1}$ Salário mínimo vigente à época: $R \$ 545,00$.

Os homens conformaram a maioria dos entrevistados em ambas as cidades $(58,82 \%$ e $76,00 \%$ ). As médias de idade foram entre 47,64 e 54,64 anos, sendo que $76,47 \%$ e $72,00 \%$ dos entrevistados eram pessoas casadas (Tabela 1), respectivamente, para PEN e PRC. O grau de escolaridade formal era baixo. Somados os grupos até aqueles que possuíam o ensino médio completo, os totais foram de $88,23 \%$ e $96,00 \%$. O grupo com maior percentual de pessoas foi o dos indivíduos que estudaram até o nível fundamental completo, 35,29\%, na cidade de PEN e o dos que nunca estudaram, 32,00\%, em PRC.

Para a realização da pesquisa, não houve um direcionamento pelo sexo do entrevistado. Todavia, a grande maioria das entrevistas ocorreu com homens. Por conseguinte, é possível que esse fato reflita serem eles os responsáveis pelas compras da família quando relacionadas às feiras livres. O mesmo perfil foi encontrado por Silva et al. (2016); Figueiro et al. (2014) e Rocha et al. (2010), que constataram serem os homens a maioria dos consumidores em feiras livres dos estados do Amazonas, Pará e do Rio Grande do Sul, respectivamente. No gerenciamento das atividades domésticas, dentre as quais se inclui a compra dos mantimentos, as mulheres respondem pela maior parte dos trabalhos realizados. Desta feita, as observações efetuadas com esta pesquisa, na qual os homens despontaram como maioria presente nas feiras, contrasta com o quadro mencionado.

Há de se ressaltar que não se exclui aqui a presença de mulheres nas feiras estudadas, mas tão somente que foram os homens os que responderam os questionários da pesquisa em maior percentual. Mesmo que se possa aventar que o menor número de mulheres realizando compras nas feiras livres se deve ao fato delas estarem cuidando de outros trabalhos domésticos, como atestaram Silva et al. (2016), no caso específico da feira livre realizada em Juruá - AM, para o presente trabalho não se pode afirmar tal posição.

Ainda com relação às questões de gênero, acredita-se não ser possível afirmar que os homens teriam maior preferência pelas curimatãs-pacu do que as mulheres, tendo em vista que 64,42\% dos 104 em PEN e 62,86\% dos 105 entrevistados em PRC eram do sexo masculino. Assim, entende-se que o maior número de entrevistados deste gênero resultou em maior número de homens que preferem a espécie. Esta maioria de homens dentre os entrevistados, ainda que tenha 
ocorrido devido ao maior número de pessoas deste sexo dentre os consumidores na feira, ajuda a explicar a baixa escolarização formal média da amostra analisada, tendo em vista que as mulheres possuem maior média de anos de estudo no Brasil (IBGE, 2019).

No que concerne ao número médio de habitantes por residência, este é maior em $\operatorname{PEN~}(3,82$ pessoas) do que em PRC (3,39 pessoas). Comparando as duas cidades, as médias de rendimentos salariais por família também são maiores em PEN, na qual até $76,47 \%$ dos entrevistados declararam renda de até três salários mínimos. Em PRC, para 96,00\% das pessoas entrevistadas, o teto salarial era de até três salários mínimos. Entretanto, chama a atenção o fato de que 35,29\% e 36,00\% dos entrevistados, respectivamente, para PEN e PRC, informaram possuírem renda inferior a um salário mínimo vigente à época. De acordo com o PNUD (2013), Alagoas era, em 2010, o terceiro estado brasileiro com a pior renda per capita ( $R \$ 432,56)$, enquanto a média nacional era de $R \$ 793,87$. Ainda segundo o Instituto, as rendas per capita em PEN (R\$ 339,15) e PRC (R\$ 195,26) eram inferiores às médias nacional e estadual, o que justifica o alto percentual de pessoas com renda inferior a um salário mínimo e na faixa entre um e três salários mínimos. Obviamente, as baixas rendas declaradas determinam o poder de compra dos entrevistados e limitam a capacidade de aquisição de carnes, o que inclui a curimatã-pacu.

Por intermédio das respostas obtidas para a questão acerca da carne preferida, demonstrouse que a carne bovina é a mais apreciada $(47,06 \%$ e $48,00 \%)$, vindo a ser também a carne mais consumida (58,80 e 56,00\%), evidenciando que havia relação direta entre as carnes prediletas e as mais ingeridas. Nem sempre a preferência por determinado tipo de carne se traduz em maior consumo, como evidenciam alguns estudos a respeito de preferências (Araujo et al., 2015a; 2015b), tendo em vista que há diversos fatores que interferem na decisão de compra (como o preço) e de consumo (como questões relacionadas à saúde). Nos estudos de Panello et al. (2016), realizado em Piracicaba - SP; Santos et al. (2016), em Maceió - AL; e o de Lopes et al. (2016), em diferentes regiões brasileiras, a carne bovina foi apontada como a predileta, seguida pela carne de aves e de peixes, o que parece ser, em geral, o padrão na maior parte do país.

Os dados apresentados na Tabela 2 tratam da frequência de consumo e preferência pelos peixes de acordo com o seu habitat. Em PEN e PRC, respectivamente, 64,71\% e 76,00\% dos entrevistados afirmaram consumirem peixes mais de uma vez por semana. Somando-se estes percentuais aos dos que afirmaram consumir peixes todos os dias ou ao menos uma vez por semana, pôde-se contabilizar que $94,12 \%$ e $96,00 \%$, respectivamente, consomem peixes pelo menos uma vez por semana, o que demonstra a importância destes organismos na composição da dieta alimentar da população entrevistada.

Ainda que exista uma recomendação mundial para a quantidade de peixe a ser consumida por indivíduo ao ano e os valores médios de consumo per capita no Brasil estarem abaixo desta recomendação, como será discutido na sequência, é sabido que há muita variação nos resultados deste tipo de levantamento. Segundo Leandro et al. (2018), essas diferenças estão relacionadas à disponibilidade e ao custo do peixe e alimentos alternativos; à renda; aos fatores socioeconômicos e culturais; às tradições alimentares; aos gostos; à demanda; às estações do ano; aos preços; à infraestrutura; à saúde e ao marketing. Neste sentido, Porto et al. (2006), em estudo desenvolvido em Pelotas-RS, observaram que $28,7 \%$ das pessoas entrevistadas consumiam peixes de uma a duas 
vezes por semana, e que 64,0\% delas eventualmente. Já Maciel et al. (2019) estudaram a comercialização de peixes durante o evento denominado Semana do Peixe para os estudantes universitários de Piracicaba - SP e identificaram que apenas 10,6\% consomem pescado de uma a duas vezes por semana, 31,2\% apenas uma vez por semana e $29,4 \%$ de duas a três vezes ao mês. Em estudo de Costa Júnior et al. (2018), realizado em comunidades ribeirinhas do rio Tapajós, Itaituba - PA, em 2013 e 2014, respectivamente, 74,5\% e 95,6\% dos indivíduos acompanhados afirmaram consumir peixes entre duas e quatro refeições por semana. Os três estudos citados reforçam a diversidade de resultados que se pode obter em inquéritos nutricionais deste tipo.

No âmbito nacional, o consumo per capita anual aparente de pescado foi de 9,75 kg em 2010 (BRASIL, 2012), enquanto a FAO (2016) apontou que os valores médios foram ligeiramente inferiores, de 9,6 kg/habitante/ano entre 2013 e 2015. Ressalta-se que estes são os dados disponíveis mais próximos ao período de realização do presente estudo. É importante salientar que a FAO (2013) recomenda o consumo de $12 \mathrm{~kg} / \mathrm{habitante} / \mathrm{ano}$ de pescado, valor superior aos de consumos estimados no Brasil. Ainda que no presente estudo não tenham sido obtidas informações acerca das quantidades consumidas, considerando o consumo médio de $120 \mathrm{~g}$ de pescado por refeição e a frequência de consumo de uma vez por semana (que absorveria quase que a totalidade do grupo estudado nas duas cidades), a quantidade consumida por pessoa em um ano seria próxima a 6,257kg. Entretanto, como $64,71 \%$ e $76,00 \%$ afirmaram consumir peixes mais de uma vez por semana, se considerarmos que estes consomem duas vezes a cada semana, o consumo de, ao menos, $12,514 \mathrm{~kg} /$ pessoa/ano seria mais frequente dentre as populações estudadas, valor superior à recomendação da FAO citada anteriormente. Caso a amostragem analisada pudesse ser extrapolada para as populações de ambas as cidades (63.683 e 20.066 habitantes), considerando o número de habitantes (IBGE, 2019) e o consumo estimado e descrito acima, seriam necessárias entre 398 e 796 toneladas de pescado em PEN e entre 125 e 251 toneladas em PRC para suprir a demanda dos municípios por ano.

Tabela 2: Frequência e preferências de consumo de peixes pelos consumidores entrevistados nas feiras livres de Penedo ( $n=16$ ) e de Porto Real do Colégio $(n=27)$, Alagoas - Brasil, e que citaram a curimatã-pacu como a espécie de peixe preferida para o consumo.

\begin{tabular}{lrr}
\hline Questões Abordadas & Valores (\%) & \\
\hline & Penedo & Porto Real do Colégio \\
\hline 1. Frequência de consumo de peixes & & \\
\hline Todos os dias & 0,00 & 8,00 \\
Mais de uma vez por semana & 64,71 & 76,00 \\
Uma vez por semana & 29,41 & 12,00 \\
Mais de uma vez por mês & 5,88 & 4,00 \\
Uma vez por mês & 0,00 & 0,00 \\
\hline 2. Motivos para o consumo de peixes & & \\
\hline Pelo preço acessível & 0,00 & 4,00 \\
Variar cardápio & 23,53 & 16,00 \\
Carne saborosa & 35,29 & 48,00 \\
Carne branca & 0,00 & 0,00 \\
Questão de saúde & 41,18 & 28,00 \\
Fácil de encontrar & 0,00 & 4,00 \\
\hline 3. Gostaria de consumir peixes com maior frequência? & \\
\hline
\end{tabular}




\begin{tabular}{lrr}
\hline Sim & 70,59 & 56,00 \\
Não & 29,41 & 44,00 \\
\hline 4. Porque não consome com maior frequência? & & \\
\hline Não gosto de peixe & 0,00 & 5,88 \\
Preço elevado & 29,41 & 17,65 \\
Baixa Qualidade & 0,00 & 0,00 \\
Dificuldade de encontrar & 5,88 & 0,00 \\
Dificuldade de preparo & 5,88 & 0,00 \\
Enjoaria & 41,18 & 64,71 \\
Espinhos & 0,00 & 0,00 \\
Poucos produtos disponíveis & 0,00 & 11,76 \\
Outros motivos & 17,65 & 0,00 \\
\hline 5. Prefere consumir peixes de que ambiente? & & \\
\hline Água doce & 64,71 & 76,00 \\
Marinhos & 0,00 & 0,00 \\
Dos dois ambientes & 29,41 & 24,00 \\
Não consigo diferenciar & 5,88 & 0,00 \\
\hline
\end{tabular}

Foram entrevistados 104 consumidores de peixes em Penedo e 105 em Porto Real do Colégio, dos quais, respectivamente, 16 e 27 entrevistados citaram a curimatã-pacu como a espécie preferida para o consumo.

As principais razões alegadas pelos entrevistados como motivadoras para o consumo de peixes foram: saúde, para 41,18\% e 28,00\%; sabor, para 35,29\% e 48,00\%; e variação no cardápio, para $23,53 \%$ e $16,00 \%$, respectivamente, para PEN e PRC. Do total das pessoas que gostariam de consumir peixes com maior frequência, o percentual foi de $70,59 \%$ para a cidade de PEN e de $56,00 \%$ para a de PRC. O principal motivo alegado para a negativa em consumi-los foram: enjoariam, $41,18 \%$ e $64,71 \%$, seguido pelo preço dos peixes, $29,41 \%$ e $17,65 \%$.

Em decorrência da alta frequência do consumo de peixes, considerando a baixa renda familiar, esperava-se que o seu preço fosse a principal limitação para o não aumento do consumo. Tal expectativa adveio da seguinte elucubração: baseando-se nas rendas per capitas dos entrevistados e nos preços médios que os consumidores de ambas as cidades consideraram justos, o consumidor de PEN teria poder de compra para adquirir cerca de $49 \mathrm{~kg}$ da espécie estudada por mês, enquanto o de PRC teria poder aquisitivo para comprar $30 \mathrm{~kg}$ ao mês. Obviamente, o consumidor não exauriria toda a sua renda mensal na compra de um único produto, mas esta análise serve para demonstrar que o fator financeiro se tornaria impeditivo aos indivíduos para a compra de uma maior quantidade de pescado, tendo em vista as suas outras necessidades básicas.

Retomando a análise sobre os fatores por eles apontados para não consumirem uma maior quantidade de peixes, para ambos, os principais motivos alegados foram autoexplicativos e plausíveis. Dentre os peixes de diferentes ambientes aquáticos, os consumidores declararam preferência pelos os de água doce, 64,71\% em PEN e 76,00\% em PPRC. Como os dados analisados neste estudo são referentes aos consumidores que apontaram a curimatã-pacu como sendo a sua espécie preferida, sendo esta uma espécie de água doce, era esperado que a maioria destes preferisse consumir peixes dulciaquícolas. Ademais, ainda que algumas espécies marinhas adentrem por quilômetros subindo o Rio São Francisco, chegando até PRC, na feira livre desta cidade não era comum encontrar organismos aquáticos de origem marinha. Já em PEN, além de peixes, camarões e siris marinhos eram facilmente encontrados. É provável que pela disponibilidade de 
peixes marinhos na feira livre desta cidade, um menor percentual de consumidores afirmou que os peixes de água doce eram os seus preferidos.

Nas Tabelas 3 e 4 são apresentadas as questões mais específicas a respeito dos preços que os consumidores consideraram justos e aqueles que os fazem desistirem da compra; sobre as preferências de locais e formas de aquisição; acerca das ocasiões em que preferem consumir; e como consideram a preparação de peixes, de maneira geral (Tabela 3), bem como exclusivamente para a curimatã-pacu (Tabela 4). Os preços que os consumidores consideraram justos para peixes, sem que houvesse especificação da espécie, foram de $R \$ 6,90$ e $R \$ 6,46$, que são consideravelmente inferiores, $17,56 \%$ e $21,70 \%$ menores, aos valores considerados justos quando citada especificamente a curimatã-pacu, $R \$ 8,37$ e $R \$ 8,25$. Isto significa que a preferência pelo consumo desta espécie era proporcionalmente monetizada, realmente se traduzindo em predisposição a pagar mais para adquirir a curimatã-pacu em detrimento de outras espécies ícticas.

Ainda com relação aos preços de venda dos peixes julgados justos pelos consumidores, Leandro et al. (2018), ao analisarem o processo de comercialização de peixes em Sinope - MT, verificaram que o valor considerado justo pelos entrevistados variou entre $R \$ 12,00$ e $R \$ 17,50$ (média de $\mathrm{R} \$ 14,00$ ) por quilograma de peixe, de acordo com as classes de renda da população. Os dados apresentados no presente estudo se referem às coletas realizadas em 2013, ao passo que os daqueles autores são de 2016. Essa diferença temporal repercute no preço do produto, bem como os salários mínimos vigentes. Uma comparação de rendas médias (IBGE, 2019) demonstrou que nas cidades alagoanas estudadas, o rendimento médio por habitante formalmente empregado é menor que em Sinope - MT, bem como é maior o número de pessoas recebendo até meio salário mínimo. Porto et al. (2006), analisando características de aquisição e consumo de peixes pelos consumidores da cidade de Pelotas - RS, identificaram que a carne de peixes é a segunda considerada de preço mais justo, para $31,9 \%$ dos entrevistados, perdendo apenas para o frango, 48,3\%. No presente estudo, o preço que mais frequentemente faria os consumidores desistirem da compra de qualquer espécie de peixe foi de $\mathrm{R} \$ 12$ reais, 23,53\%, e de $\mathrm{R} \$ 10$ reais, 52,00\%, respectivamente, para PEN e PRC. Quando considerada especificamente a curimatã-pacu, $R \$ 12,00$ (31,25\%), e $R \$ 10,00$ $(52,00 \%)$, também foram os preços que fariam os consumidores desistirem da compra.

Tabela 3: Considerações dos consumidores entrevistados nas feiras livres de Penedo $(n=16)$ e de Porto Real do Colégio ( $n=27$ ), Alagoas - Brasil, e que citaram a curimatã-pacu como a espécie de peixe preferida para o consumo, sobre os locais de compra e o preço dos peixes.

\begin{tabular}{|c|c|c|}
\hline Questões Abordadas & & Valores (\%) \\
\hline \multicolumn{2}{|c|}{ Penedo } & Porto Real do Colégio \\
\hline $\begin{array}{l}\text { 1. Qual o preço }(\mathrm{R} \$ / \mathrm{Kg}) \text { que considera } \\
\text { justo para o peixe? }\end{array}$ & 6,90 & 6,46 \\
\hline \multicolumn{3}{|c|}{ 2. Qual o preço $(\mathrm{R} \$ / \mathrm{Kg})$ em que desiste de comprar o peixe? } \\
\hline Seis & 0,00 & 0,00 \\
\hline Oito & 11,76 & 0,00 \\
\hline Dez & 17,65 & 52,00 \\
\hline Doze & 23,53 & 12,00 \\
\hline
\end{tabular}




\begin{tabular}{|c|c|c|}
\hline Quatorze & 11,76 & 12,00 \\
\hline Dezesseis & 17,65 & 4,00 \\
\hline Dezoito & 0,00 & 4,00 \\
\hline Vinte & 5,88 & 4,00 \\
\hline Acima de vinte & 11,76 & 12,00 \\
\hline \multicolumn{3}{|c|}{ 3. Quais os locais onde compra - gostaria de comprar peixes? } \\
\hline Peixaria & $100,00-5,88$ & $12,50-9,09$ \\
\hline Feira livre & $0,00-82,35$ & $79,17-81,82$ \\
\hline Supermercado & $0,00-11,76$ & $8,33-9,09$ \\
\hline Mercearia & $0,00-0,00$ & $0,00-0,00$ \\
\hline Restaurante & $0,00-0,00$ & $0,00-0,00$ \\
\hline Bar & $0,00-0,00$ & $0,00-0,00$ \\
\hline Outro & $0,00-0,00$ & $0,00-0,00$ \\
\hline $\begin{array}{l}\text { Não compro } \\
\text { peixes }\end{array}$ & $0,00-0,00$ & $0,00-0,00$ \\
\hline \multicolumn{3}{|c|}{ 4. Compra - gostaria de comprar peixes em que modo de apresentação? } \\
\hline Vivos & $35,29-47,06$ & $60,00-72,00$ \\
\hline Inteiros & $58,82-47,06$ & $40,00-24,00$ \\
\hline \multicolumn{3}{|l|}{ Frescos } \\
\hline Inteiros & $0,00-0,00$ & $0,00-0,00$ \\
\hline \multicolumn{3}{|l|}{ Congelados } \\
\hline Em postas & $0,00-5,88$ & $0,00-0,00$ \\
\hline Filés frescos & $0,00-0,00$ & $0,00-0,00$ \\
\hline $\begin{array}{l}\text { Filés } \\
\text { congelados }\end{array}$ & $0,00-0,00$ & $0,00-0,00$ \\
\hline $\begin{array}{l}\text { Filés } \\
\text { empanados }\end{array}$ & $0,00-0,00$ & $0,00-0,00$ \\
\hline $\begin{array}{l}\text { Cortes } \\
\text { temperados }\end{array}$ & $0,00-0,00$ & $0,00-0,00$ \\
\hline $\begin{array}{l}\text { Empanados e } \\
\text { embutidos }\end{array}$ & $0,00-0,00$ & $0,00-0,00$ \\
\hline Enlatados & $5,88-0,00$ & $0,00-4,00$ \\
\hline \multicolumn{3}{|c|}{ 5. Em quais ocasiões prefere consumir peixes? } \\
\hline Refeições cotidianas & 76,47 & 80,00 \\
\hline Finais de semana & 17,65 & 16,00 \\
\hline Datas especiais & 0,00 & 0,00 \\
\hline Ao receber visitas em casa & 0,00 & 4,00 \\
\hline Refeições fora de casa & 0,00 & 0,00 \\
\hline Outras ocasiões & 5,88 & 0,00 \\
\hline \multicolumn{3}{|c|}{ 6. Considera o preparo dos peixes } \\
\hline Fácil & 70,59 & 64,00 \\
\hline Difícil & 5,88 & 24,00 \\
\hline Igual ao das outras carnes & 23,53 & 12,00 \\
\hline
\end{tabular}

Foram entrevistados 104 consumidores de peixes em Penedo e 105 em Porto Real do Colégio, dos quais, respectivamente, 16 e 27 entrevistados citaram a curimatã-pacu como a espécie preferida para o consumo.

Todos os consumidores entrevistados em PEN afirmaram que o principal local no qual adquirem peixes é na peixaria, ainda que $82,35 \%$ deles elejam a feira livre como o local preferido 
para efetuar a compra. Já em PRC, 79,17\% adquirem peixes e 81,82\% realmente preferem adquirir na feira livre. Como será melhor discutido a seguir, os consumidores entrevistados preferem comprar peixes vivos, principalmente em PRC. Desta feita, a preferência nestas cidades pela aquisição de peixes nas feiras livres era o comportamento esperado.

Neste sentido, Lustosa et al. (2008), em uma análise da cadeia produtiva da piscicultura no Baixo Rio São Francisco, que inclui os municípios de PEN e PRC, diagnosticaram que os principais produtos desta cadeia eram peixes inteiros in natura e que, em sua maioria, os mesmos eram comercializados nas feiras livres da região. Tal assertiva reforça a importância deste local para a venda de pescados. Todavia, chama a atenção o fato de todos os 16 entrevistados que tinham a curimatã-pacu como espécie predileta na cidade de Penedo terem afirmado que o principal local no qual adquiriam peixes, não especificamente a espécie-alvo nesta pesquisa, eram as peixarias. Esta conclusão causa estranhamento, principalmente pelo fato de ser a feira livre o mais importante canal de comercialização de peixes na cidade. Talvez, por conta da limitação da disponibilidade de peixes, concentrada aos sábados, bem como devido ao fato que a maior parte dos consumidores consome peixes mais de uma vez por semana e preferem peixes frescos, isto motive os mesmos a buscarem locais alternativos para compras em outros dias da semana. Ademais, sabe-se que em ambas as cidades alguns vendedores (tanto os que são pescadores vendendo sua produção pesqueira, quanto os que são apenas comerciantes) fazem vendas "porta a porta", entregando peixes frescos diretamente aos consumidores em suas residências.

Tabela 4: Conhecimento sobre a produção local, frequência e preferências de consumo da curimatã-pacu pelos consumidores entrevistados nas feiras livres de Penedo $(n=16)$ e de Porto Real do Colégio $(n=27)$, Alagoas - Brasil, e que citaram esta espécie de peixe como a preferida para o consumo.

\begin{tabular}{lrr}
\hline Questões Abordadas & \multicolumn{2}{c}{ Valores (\%) } \\
\hline & \multicolumn{1}{l}{ Penedo } & Porto Real do Colégio \\
\hline 1. Sua região é produtora de curimatã-pacu? & 68,75 & \\
\hline Sim & 31,25 & 70,00 \\
Não & & 30,00 \\
\hline 2. Frequência de consumo de curimatã-pacu & 0,00 & 15,00 \\
\hline Todos os dias & 75,00 & 40,00 \\
Mais de uma vez por semana & 12,50 & 40,00 \\
Uma vez por semana & 6,25 & 0,00 \\
Mais de uma vez por mês & 0,00 & 0,00 \\
Uma vez por mês & 6,25 & 5,00 \\
Outra & & 0,00 \\
\hline 3. Motivos para o consumo de curimatã-pacu e não de outro peixe & 6,25 & 90,00 \\
\hline Pelo preço acessível & 81,25 & 0,00 \\
Carne saborosa & 12,50 & 0,00 \\
Carne branca & 0,00 & 10,00 \\
Questão de saúde & 0,00 & \\
Fácil de encontrar & & 55,00 \\
\hline 4. Gostaria de consumir curimatã-pacu com maior frequência? & 45,00 \\
\hline Sim & 56,25 & \\
Não & 43,75 & \\
\hline 5. Porque não consome - porque não gostaria de consumir com maior frequência? &
\end{tabular}




\begin{tabular}{|c|c|c|}
\hline Preço elevado & $55,56-14,29$ & $36,36-0,00$ \\
\hline Baixa Qualidade & $0,00-0,00$ & $0,00-0,00$ \\
\hline Dificuldade de encontrar & $0,00-0,00$ & $9,09-0,00$ \\
\hline Dificuldade de preparo & $11,11-0,00$ & $0,00-0,00$ \\
\hline Enjoaria & $11,11-85,71$ & $18,18-100,00$ \\
\hline Espinhos & $0,00-0,00$ & $0,00-0,00$ \\
\hline Poucos produtos disponíveis & $0,00-0,00$ & $0,00-0,00$ \\
\hline Outros motivos & $22,22-0,00$ & $36,36-0,00$ \\
\hline \multicolumn{3}{|l|}{ 6. Prefere comprar curimatãs-pacu } \\
\hline Vivas & 56,25 & 75,00 \\
\hline Inteiras frescas & 37,50 & 20,00 \\
\hline Inteiras congeladas & 0,00 & 0,00 \\
\hline Abatidas e completamente limpas & 0,00 & 0,00 \\
\hline Em postas & 6,25 & 0,00 \\
\hline Filés frescos & 0,00 & 0,00 \\
\hline Filés congelados & 0,00 & 0,00 \\
\hline Filés empanados & 0,00 & 0,00 \\
\hline Cortes temperados & 0,00 & 0,00 \\
\hline Empanadas e embutidas & 0,00 & 0,00 \\
\hline Enlatadas & 0,00 & 0,00 \\
\hline Outros & 0,00 & 5,00 \\
\hline 7. Qual o preço justo (R\$/Kg) para a curimatã-pacu? & 8,37 & 8,25 \\
\hline \multicolumn{3}{|c|}{ 8. Qual o preço (R\$/Kg) em que desiste de comprar curimatã-pacu? } \\
\hline Seis & 0,00 & 0,00 \\
\hline Oito & 6,25 & 0,00 \\
\hline Dez & 18,75 & 45,00 \\
\hline Doze & 31,25 & 25,00 \\
\hline Quatorze & 18,75 & 10,00 \\
\hline Dezesseis & 18,75 & 5,00 \\
\hline Dezoito & 0,00 & 5,00 \\
\hline Vinte & 0,00 & 0,00 \\
\hline Acima de vinte & 6,25 & 10,00 \\
\hline \multicolumn{3}{|c|}{ 9. Considera a qualidade do curimatã-pacu comercializado no seu município } \\
\hline Ótima & 12,50 & 20,00 \\
\hline Boa & 75,00 & 70,00 \\
\hline Regular & 12,50 & 10,00 \\
\hline Ruim & 0,00 & 0,00 \\
\hline Péssima & 0,00 & 0,00 \\
\hline Desconheço & 0,00 & 0,00 \\
\hline
\end{tabular}

Foram entrevistados 104 consumidores de peixes em Penedo e 105 em Porto Real do Colégio, dos quais, respectivamente, 16 e 27 entrevistados citaram a curimatã-pacu como a espécie preferida para o consumo.

A soma dos percentuais de consumidores que afirmaram consumir curimatãs-pacu ao menos uma vez por semana em ambas as cidades foi $87,50 \%$ e $95,00 \%$, valores que são similares aos observados para a frequência geral de consumo de peixes, $94,12 \%$ e $96,00 \%$, para PEN e PRC. Dentre os motivos alegados para justificar o consumo da espécie em detrimento de outros peixes, 0 principal foi o sabor da carne, $81,25 \%$ e $90,00 \%$, o que é facilmente justificável, já que os valores apresentados neste estudo são um extrato daqueles oriundos de entrevistados que apontaram ser 
esta a sua espécie favorita. Parcela superior a $50 \%$ dos consumidores gostariam de consumir mais a espécie, entretanto, $85,71 \%$ e $100,00 \%$ deles alegaram que não consumiriam mais porque enjoariam. Os percentuais de consumidores que alegaram que não consomem peixes mais vezes porque enjoariam são menores do que os que alegaram o mesmo motivo para o não consumo de curimatãs-pacu, demonstrando que ao tratar especificamente de um tipo de alimento há maior percepção da necessidade de variação na ingestão. Neste estudo, como o consumo declarado de peixes é alto e a espécie preferida é a curimatã-pacu, pode-se interpretar que o seu consumo já ocorre em alta frequência e que, diante da existência da diversidade de outros peixes e demais alimentos, este motivo é mais que justificável para o não aumento do consumo.

A respeito das formas de apresentação do pescado, em PEN, 35,29\% dos compradores adquirem peixes vivos e $47,06 \%$ preferem assim os adquirir, na medida em que em PRC, 60,00\% realizam a compra dos organismos ainda vivos, com o percentual de $72 \%$ para os que assim os preferem comprar. Os peixes inteiros frescos são a outra forma de apresentação de venda na qual significativa parcela dos entrevistados apontou comprar, 58,82\% e 40,00\%, e preferiam comprar $47,06 \%$ e 24,00\%. Quando questionados, especificamente, com relação à curimatã-pacu, 56,25\% e $75,00 \%$ preferiam comprar os animais vivos, enquanto $37,50 \%$ e $20,00 \%$ preferiam adquiri-los inteiros e frescos.

A preferência dos consumidores pela aquisição de peixes vivos, que são submetidos à exposição aérea nas bancas até o abate para a venda ou mesmo até a morte dos animais, já foi previamente relatada para ambas as cidades estudadas e pode ser melhor compreendida no trabalho de Araujo et al. (2015b). Para melhor compreensão, ressalta-se, contudo, que as feiras de ambas as cidades onde a pesquisa foi realizada não são feiras de peixes vivos, ou seja, não há estrutura de tanques para manutenção dos animais vivos. Estes são colocados vivos nas bancas até o momento da venda.

Com relação às situações de consumo de peixes, os dados possibilitaram afirmar que não há a necessidade de ocorrência de situações tidas como especiais para estimularem o consumo por parte desta população, uma vez que $76,47 \%$ e $80,00 \%$ afirmaram que comiam peixes em situações cotidianas. A maioria destes consumidores julgou o preparo dos peixes como fácil, 70,59\% e 64,00\%. Leandro et al. (2018) observaram que $14,00 \%$ de seus entrevistados afirmaram consumir peixes em refeições diárias, à medida que $7,00 \%$ deles declararam que os consumiam em datas comerciais. Com relação à qualidade que atribuíam às curimatãs-pacu comercializadas nas feiras livres, retomando as cidades alvo da presente pesquisa, $87,50 \%$ e $90,00 \%$ consideraram como boa ou ótima, o que demonstra alto grau de satisfação com o produto oferecido na região.

$\mathrm{Na}$ Tabela 5 podem ser observados os dados referentes ao conhecimento do comprador sobre a origem da curimatã-pacu, sua propensão a pagar mais por peixes produzidos de maneira responsável e por cortes especiais. A maior parte das pessoas, $70,59 \%$ e $72,00 \%$, possui conhecimento de que a localidade é uma região produtora de curimatãs-pacu. $76,47 \%$ e 52,00\% dos entrevistados asseveraram que estariam dispostos a pagar mais por espécimes produzidas em seu município e de forma responsável. Com relação a pagar mais por cortes especiais de curimatã-pacu, $52,94 \%$ e $44,00 \%$ afirmaram positivamente. Ainda que Zuin e Zuin (2007) afirmem haver uma crescente busca por alimentos diferenciados e que os consumidores passaram a privilegiar a 
qualidade presente nos alimentos tradicionais, como é o caso da espécie estudada para os residentes das cidades do Baixo Rio São Francisco, persiste uma parcela significativa de pessoas, em ambas as cidades pesquisadas, que não estaria disposta a pagar mais por saber ser a espécie um alimento produzido localmente, ainda que considere ser de boa qualidade.

Tabela 5: Considerações dos consumidores entrevistados nas feiras livres de Penedo $(n=16)$ e de Porto Real do Colégio ( $n=27$ ), Alagoas - Brasil, e que citaram a curimatã-pacu como a espécie de peixe preferida para o consumo, sobre cortes especiais e produção local responsável.

\begin{tabular}{|c|c|c|}
\hline Questões Abordadas & & Valores (\%) \\
\hline & Penedo & Porto Real do Colégio \\
\hline \multicolumn{3}{|c|}{ 1. Sabe onde são produzidos os peixes que compra? } \\
\hline Na Região & 70,59 & 72,00 \\
\hline Fora da Região & 0,00 & 4,00 \\
\hline Fora de Alagoas & 0,00 & 8,00 \\
\hline Não sei & 17,65 & 16,00 \\
\hline Não me importo & 11,76 & 0,00 \\
\hline \multicolumn{3}{|c|}{ 2. Pagaria mais por peixes produzidos de forma responsável no seu município? } \\
\hline Sim & 76,47 & 52,00 \\
\hline Não & 23,53 & 48,00 \\
\hline \multicolumn{3}{|c|}{ 3. Pagaria mais por cortes especiais de peixes? } \\
\hline Sim & 52,94 & 44,00 \\
\hline Não & 47,06 & 56,00 \\
\hline
\end{tabular}

Foram entrevistados 104 consumidores de peixes em Penedo e 105 em Porto Real do Colégio, dos quais, respectivamente, 16 e 27 entrevistados citaram a curimatã-pacu como a espécie preferida para o consumo.

\section{CONCLUSÃO}

Como espécie nativa da bacia hidrográfica do Rio São Francisco, a curimatã-pacu é a terceira espécie preferida pelos entrevistados, sendo a primeira dentre as nativas, em ambas as cidades, nas quais as tilápias e tambaquis são as prediletas. Tendo em vista esta preferência dos consumidores, o fato da produção de tilápias e tambaquis na região ser bastante superior à de curimatãs-pacu e, somando-se a isto, por esta última ser um dos mais importantes recursos ícticos explorados na pesca continental da região, maior atenção deve ser dada à sua conservação. Pôde-se constatar, ainda, que devido à preferência de aquisição de curimatãs-pacu vivas, a comercialização da espécie nas cidades estudadas é totalmente dependente das feiras livres na condição de seu principal canal de comercialização, notadamente para os pequenos comerciantes. Neste sentido, seria prolífica a realização de esforços dos entes públicos e privados no sentido de possibilitarem o desenvolvimento da comercialização de peixes no modelo de "feira do peixe vivo", o que poderia agregar maior valor aos produtos. Isto também auxiliaria na mitigação de problemas éticos relacionados ao bem-estar dos peixes durante o abate. Ademais, pode-se dizer que os consumidores estão relativamente bem informados a respeito da importância da região para a produção da espécie em análise e estão dispostos a valorizar economicamente a produção local responsável. 


\section{REFERÊNCIAS}

Almeida, E.O.; Santos, R.B.; Coelho Filho, P.A.; Cavalcante Junior, A.; Souza, A.P.L.; Soares, E.C. (2018). Polyculture of curimatã pacu and freshwater prawn. Boletim do Instituto de Pesca, 41(2): 271-278.

Araujo, D.M.; Lins, J.L.F.; Tavares, A.S.; Bordinhon, A.M.; Pinto, L.G.Q. (2015a). Aspectos de aquisição e consumo de peixes na feira livre da cidade de Penedo-Alagoas. Boletim do Instituto de Pesca, 41(2): 429-440.

Araujo, D.M.; Lins, J.L.F.; Tavares, A.S.; Silva, J.; Silva, V.M.; Bordinhon, A.M. (2015b). Aspectos de aquisição e consumo de peixes na feira livre de Porto Real do Colégio - Alagoas. Boletim do Instituto de Pesca, 41(4): 961-973.

Araújo, J.S.; Sá, M.F.P. (2018). Sustentabilidade da piscicultura no baixo São Francisco alagoano: condicionantes socioeconômicos. Ambiente e Sociedade, 11(2): 405-424.

Bowen, S.H. (1983). Detritivory in neotropical fish communities. Environmental Biology of Fishes, 9(2): 137-144.

Braga, T.M.P.; Silva, A.A.; Rebêlo, G.H. (2016). Preferências e tabus alimentares no consumo de pescado em Santarém, Brasil. Novos Cadernos NAEA, 19(3): 189-204, 2016.

BRASIL. (2012). Ministério da Pesca e Aquicultura. Boletim estatístico da pesca e aquicultura. Brasil 2010. Brasília: MPA.

Campos, W.N. (2009). Análise comparativa da variação genética entre os estoques cultivado e natural de Prochilodus argenteus: implicações para o repovoamento de rios (Dissertação de Mestrado). Universidade Federal de São Carlos, São Paulo, SP, Brasil.

Castro, R.; Vari, R.P. (2004). Detritivores of the South American fish family Prochilodontidae (Teleostei: Ostariophysi: Characiformes): a phylogenetic and revisionary study. Smithsonian Contributions to Zoology, 622: 1-189.

Coelho, A.B.; Aguiar, D.R.D.; Fernandes, E.A. (2009). Padrão de consumo de alimentos no Brasil. Revista de Economia e Sociologia Rural, 47(2): 335-362.

Costa Júnior, J.M.F.; Silva, C.I.M.; Lima, A.A.S.; Rodrigues Júnior, D.; Silveira, L.C.L.; Souza, G.S.S.; Pinheiro, M.C.N. (2018). Teores de mercúrio em cabelo e consumo de pescado de comunidades ribeirinhas na Amazônia brasileira, região do Tapajós. Ciência \& Saúde Coletiva, 23(3): 805-812.

FAO. (2013). National Aquaculture Sector Overview. Brazil. Rome: FAO. Recuperado de: http://www.fao.org/fishery/countrysector/naso_brazil/en

FAO. (2016). The State of World Fisheries and Aquaculture 2016. Contributing to Food Security and Nutrition for All. 200p.

Godinho, H. P.; Godinho, A. L. (2003). Águas, peixes e pescadores do São Francisco das Minas Gerais. Editora PUC Minas. 
IBGE. Instituto Brasileiro de Geografia e Estatística. (2019a). Pesquisa Nacional por Amostra de Domicílio - PNAD: Educação. Rio de Janeiro. Recuperado de: https://biblioteca.ibge.gov.br/visualizacao/livros/liv101657_informativo.pdf

IBGE. Instituto Brasileiro de Geografia de Estatística. (2019b). Censo Demográfico. Cidades. Recuperado de: https://cidades.ibge.gov.br/brasil/al/penedo/panorama

Jablonski, B. (2010). A divisão de tarefas domésticas entre homens e mulheres no cotidiano do casamento. Psicologia, Ciência e Profissão, 30(2): 262-275.

Leandro, S.V.; Oliveira, S.S.; Moreira, P.S.A.; Otani, F.S. (2018). Perfil de consumo e do consumidor de peixe do município de Sinop, Mato Grosso. Agroecossistemas, 10(1): 73-98.

Lopes, A.C.M. (2010). Diversidade genética das espécies de Prochilodus spp. Utilizadas em piscicultura no baixo São Francisco no Estado de Sergipe. (Dissertação de Mestrado). Universidade Tiradentes. Aracaju, SE, Brasil.

Lopes, I.G.; Oliveira, R.G.; Ramos, F.M. (2016). Perfil do consumo de peixes pela população brasileira. Biota Amazônia, 6(2): 62-65.

Lustosa, M.C.J.; Lages A.M.G.; Araújo, J.S. (2008). O velho Chico e sua nova cadeia produtiva: diagnóstico da piscicultura alagoana. EDUFAL.

Maciel, E.S.; Savay-Da-Silva, L.K.; Galvão, M.O.; Oetterer, M. (2015). Atributos de qualidade do pescado relacionados ao consumo na cidade de Corumbá, MS. Boletim do Instituto de Pesca, 41(1): 199-206.

Maciel, E.S.; Kato, H.C.A.; Sonati, J.G.; Galvão, J.A.; Savay-Da-Silva, L.K.; Oetterer, M. (2019). Avaliação do consumo de pescado durante campanha de incentivo em comunidade universitária. Revisa Ciência em Extensão, 15(1): 93-100.

Martins, E.F.F. (2017). Dinâmica do perfil de ácidos graxos e composição de lipídeos em músculo de reprodutores, ovócitos e larvas das espécies Brycon orthotaenia (Günther, 1864) e Prochilodus argenteus (Spix \& Agassiz, 1829). (Tese de Doutorado). Universidade Federal de Minas Gerais. Belo Horizonte, MG, Brasil.

Mascarenhas, G.; Dolzani, M.C.S. (2008). Feira Livre: territorialidade popular e cultura na metrópole contemporânea. Revista Ateliê Geográfico, 2(2): 72-87.

Nelson, J.S.; Grande, T.C.; Wilson, M.V.H. (2016). Fishes of the world. Fifth edition. John Wiley \& Sons, Inc. Hoboken, New Jersey.

PNUD - Programa das Nações Unidas para o Desenvolvimento. (2013). Relatório do Desenvolvimento Humano 2013: a ascensão do Sul - progresso humano num mundo diversificado. Recuperado de: http://www.pnud.org.br/arquivos/rdh-2013.pdf

Rocha, C.H.; Costa, C.; Castoldi, F.L.; Cecchetti, D.; Calvete, E.O.; Lodi, B.S. (2010). Perfil socioeconômico dos feirantes e consumidores da feira do produtor de Passo Fundo, RS. Ciência Rural, 40(12): 2593-2597. 
Santos, E.L.; Oliveira, W.D.S.; Soares, E.C., Lima, M.R.; Silva, L.L.A.; Machado, S.S.; Silva, J.M.; Silva, C.F.; Silva, F.F. (2018). Exigência de proteína bruta para juvenis de curimatã-pacu. Arquivo Brasileiro de Medicina Veterinária e Zootecnia, 70(3): 921-930.

Santos, E.L.; Garcia, P.H.M.; Soares, E.C.; Machado, S.S.; Silva, J.M.; Oliveira, W.D.S. (2016). Perfil do consumo de peixes na cidade de Maceió, Alagoas. Revista Científica de Produção Animal, 18(1): 45-54.

Schneider, B.C.; Silva, S.M.; Assunção, M.C.F. (2014). Consumo de Carnes por Adultos do Sul do Brasil: Um Estudo de Base Populacional. Ciência \& Saúde Coletiva, 19(8): 3583-3592.

Silva, F.J.F.; Aride, P.H.R.; Santos, S.M.; Pantoja-Lima, J.; Oliveira, A.T. (2016). Compra de pescado na feira de Juruá: fatores que influenciam na tomada de decisão. Revista de Educação, Ciência e Tecnologia do IFAM, 10(1): 16-24.

Soares, E.C.; Bruno, A.M.S.; Lemos, J.M.; Santos, R.B. (2011). Ictiofauna e pesca no entorno de Penedo, Alagoas. Biotemas, 24(1): 61-67.

Sousa, T.D.G. (2018). Etnoecologia da pesca artesanal e percepção ambiental sobre os impactos à ictiofauna no Submédio e Baixo São Francisco (Dissertação de Mestrado). Universidade Federal de Sergipe. São Cristóvão, SE, Brasil.

Teixeira, M.M.; Silva, V.B. (2015). Comportamento de Compra dos Consumidores em Mercados de Bairros. Revista Brasileira de Pesquisas de Marketing, Opinião e Mídia, 16(1): 62-85.

\section{COMO CITAR ESTE ARTIGO:}

Araújo, D. DE M, Tamano, L. T. O., Nascimento, C. W. S. DO., Tavares, K. A. S., Lins, J. L. F., SILVA, J. DA. (2020). Curimatã-Pacu como espécie preferida pelos consumidores em feiras livres do baixo Rio São Francisco, Alagoas - Brasil. Holos. 36(6), 1-22.

\section{SOBRE OS AUTORES}

\section{DE M. ARAÚJO}

Zootecnista (UFAL). Mestre em Nutrição e Produção Animal (UFPB). Doutor em Nutrição e Produção Animal (FMVZ/UNESP, Botucatu - SP). E-mail: daniel.araujo@ifal.edu.br

ORCID ID: http://orcid.org/0000-0003-0700-9836

\section{T. O. TAMANO}

Historiadora (UFAL). Mestre em História Social (USP). Doutora em História Social (USP).

E-mail: luanatamano@yahoo.com.br

ORCID ID: https://orcid.org/0000-0001-7375-2674

\section{W. S. DO NASCIMENTO}

Mestranda pelo Programa de Pós-Graduação em Tecnologias Ambientais (PPGTEC) do Instituto Federal de Alagoas (IFAL). E-mail: cynthiasouza19@gmail.com

ORCID ID: https://orcid.org/0000-0002-7536-3864

\section{K. A. S. TAVARES}

Mestranda pelo Programa de Pós-Graduação em Tecnologias Ambientais (PPGTEC) do Instituto Federal de 
Alagoas (IFAL). E-mail: kadja.geo@gmail.com

ORCID ID: https://orcid.org/0000-0002-3186-4907

\section{J. L. F. LINS}

Técnico em Agropecuária (IFAL), Zootecnia (UFAL) e Mestrando em Tecnologias Ambientais (PPGTEC - IFAL). E-mail: joaolukasfarias@yahoo.com.br

ORCID ID: https://orcid.org/0000-0002-9562-3694

\section{J. DA SILVA}

Mestre em Aquicultura pelo Centro de Aquicultura da UNESP, Jaboticabal-SP.

E-mail: biologiajoseane@gmail.com

ORCID ID: https://orcid.org/0000-0003-4208-6116

Editor(a) Responsável: Francinaide de Lima Silva Nascimento Pareceristas Ad Hoc: André Castro, Marcio Rato e Dariane Schoffen Enke

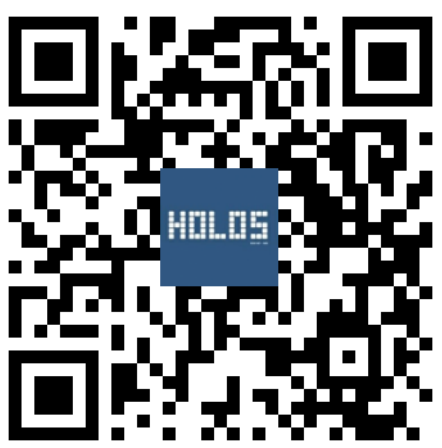

